\title{
Technical politics
}

Technical politics is the central concept of Feenberg's critical theory of technology, the point around which everything else turns. Even the ontological dilemmas in his theory are resolved here, in his thinking of the technical as political. Whereas earlier critical theorists perceived technology as the most dense point in a system that smothered the human capacity for self-emancipation, Feenberg argues that it now presents openings for democratic intervention, and he puts forward a strategic, political conception of the kinds of dispute over technology design and use that are increasingly common in digital culture. Feenberg's project differs markedly from that of earlier critical theories, then, in finding overt political significance in technical practices.

To develop critical theory in this direction, Feenberg advances a distinctive concept of hegemony, a close conceptual relative of the idea of reification discussed in Chapter 1 (Section 2). As we saw in the last chapter, the bias of technology is maintained by a sheen of neutrality that ensures it comes to appear necessary while resistance to it seems nothing short of irrational. This reified appearance can be broken down in practice when people engage in active experiences that move beyond compliance and become experimental. In this way, technical activity has the potential to become a form of political praxis, breaking the hold of controlling illusions. Once people learn to dabble in technologies and to achieve more with their devices than the set of functions stipulated by the manual ${ }^{1}$ then technological reality begins to come into focus. That reality is one of indeterminacy and open-ended experimentation, in which objects are remediated by their users and may become resistant to the identities imposed on them by manufacturers, corporations and governments.

Reconfiguration of their sensuous relationship with devices and machines dissolves the illusion of objective necessity and points technology users towards further experimentation and alternative possible 
uses. This dissolution of technology's authority in a popular culture of hacking and dabbling is, in Feenberg's theorisation, a political process. People breaking the rules of technology use has consequences which, taken in the round, constitute an extension of democracy. Feenberg argues that technology as currently designed is a key element in the maintenance of political hegemony and that popular technical interventions are subversive of this. Progressive technical politics involves articulating and channelling these interventions into a concerted struggle against technological hegemony.

The concept of hegemony is central to Feenberg's thesis that popular interventions in technical domains constitute the principal form of authentic politics in contemporary societies. Hegemony, as formulated by Marxist theorist Antonio Gramsci, is a form of domination that works through cultural media of representation. ${ }^{2}$ A party or social class is hegemonic when its favoured version of the elements of cultural life, in which a society represents itself to its members, are embraced and accepted by the majority. There is a clear affinity between this idea and formal bias, in which specific designs present themselves as the neutral form of current technical capabilities and this appearance of neutrality is a sheen on injustice and exclusion. Hegemony is a political concept, though, and understanding how it works gives insight into its thoroughly contested character and the possibility of political strategies based on this. Section 1 describes Gramsci's theory and provides a brief discussion of his understanding of the role of technology in maintaining capitalist domination.

Feenberg extends the idea of hegemony into the domain of modern technology design and use through his idea of the technical code, which is the focus of Section 2. The technical code structures the field of technical politics. Its impress is what connects individual technologies into the wider web of connected artefacts that constitutes the technical in modern societies. It is written into all objects that are recognisable as technology. As previously noted, as code it is both determinate for the social position of the artefact, conferring upon it a certain reified status in the eyes of its human users, and subject to modification by them - it can be rewritten. It is in grasping the space of underdetermined play with technical elements, and the possibility of multiple alternative concatenations of elements into designs that may serve different purposes, that Feenberg finds the radical potential in constructivism.

As discussed in Chapter 1, constructivist studies of social shaping identify the social processes that constitute new technologies in development. Viewed through the lens of critical theory, constructivist studies display the reality of technology as a social process as against its conventional appearance as a realm of reified facts that embody and corroborate established ways of doing things. The idea of the technical code, which 
works through the agency of constructivism's social groups to 'condense' particular social values with technical considerations in specific designs, politicises constructivism's central insights.

Section 3 discusses the relationship between technical politics and Ernesto Laclau and Chantal Mouffe's (1985) theory of radical democracy. Their famously 'post-Marxist' interpretation of the politics of counterhegemony is focused on the capacity of political discourse to produce radical re-articulations of dominant ideas aimed at shifting the dominant conception of society, which they construe as a limit or horizon, in order to change the prevailing sense of what is possible. Feenberg adapts these ideas to advance his idea of democratic technical politics as a series of contests for control over the technical code. This involves synthesising the idea of the technical code with the concept of political hegemony.

According to Feenberg, hegemony in contemporary societies is technological in character. The technical code is open to contestation and dispute, as constructivist analyses show, but these disputes go on under a horizon that limits what can count as a valid intervention or a legitimate technical statement. Just as political discourse has rules that constrain what may be said and done as consistent with social reality, so only some kinds of action will be recognised as technical. This sense of what technology is (its identity) is how human beings experience the weight of what Feenberg calls hegemonic technological rationality. It is the culturally dominant, hegemonic articulation of the technical code and, as such, it pervades people's experiences with modern technology.

On Laclau and Mouffe's understanding of the political, it involves changing the way that society is experienced as real - that is, the nature and position of the limit it sets on what may be proposed and what may be done. The politics of articulation involve attempts to shift this boundary by loosening the hold of hegemonic equivalences and creating spaces for excluded and suppressed experiences to gain expression. This resonates with Feenberg's search for a bridging concept between the small-scale disputes over individual artefacts described by constructivism and the wider concern with democratic change that defines his critical theory.

Section 4 examines Feenberg's synthesis of Laclau and Mouffe's concept of politics with the issue of technological transformation. The political theory of radical democracy rests on a distinctive ontology, which is the notion of a necessary yet intolerable absence, and this negative ontological premise is central to Feenberg's thought. Just as political institutions, law, morality and other 'superstructural' layers are social products perceived and lived as ontological givens over which people have no control, so technology is a reified social product. Just as radical democracy tries to shift the limits of what the state and other institutions can do, and even the form they can take, by creating subversive articulations of political discourse, so democratic technical politics 
is aimed at moving what Feenberg calls the 'boundary of technique' towards a more ambitious, more humane technology than the machines that have been produced to date.

Section 5 explores Feenberg's understanding of the goal of the technical politics of transition, which he sometimes characterises as 'civilisational change'. At this point in the theory he posits a kind of aggregate outcome for the various fronts of struggle and contestation opened up by democratic technical politics. Just as the technical code involves a series of equivalences and articulations that reproduce modernity's idea of itself as 'technological civilisation', so, Feenberg argues, socialist civilisation will manifest the unity of a different hegemonic ordering defined by a culture of vibrant democratic participation and a humanised aesthetic. In conclusion, the chapter lodges some reservations about the viability of technical politics, asking in particular if Feenberg moves too quickly to a political theorisation of technical practices at the cost of a neglect of social factors that bear upon exclusion and marginalisation in technical culture.

\section{Hegemony and technology}

The principal source for the concept of hegemony is Antonio Gramsci, a Marxist thinker of the 1920s and 1930s, contemporary with Lukàcs. Whereas the latter, and later the Frankfurt School, concerned themselves with the cultural ramifications of reification, Gramsci's main focus was on political strategy. ${ }^{3}$ The key question that confronted all of these thinkers was how to move from multiple specific practices in which the dominant illusion, or the illusions that sustained domination, were decomposed and broken down to a broader perspective that applies the same realism to the question of the character of society as whole. Feenberg draws on the idea of hegemony to advance a strategic conception of technical politics, in which hacktivist and grass roots technical interventions and movements are connected through an internal logic that points towards wider change.

In practice, the experience of an individual or a group of workers includes demystification, in the sense that they really get to know how things work (or don't) and view management ideas, for example, with a healthy scepticism. Extending such demystification into a critical perspective on society at large is not straightforward because of reification and the hold of dominant ideological representations. As we have seen, the Frankfurt School largely neglected to explore this as a political question, considering such a level of thematisation as essentially out of reach in a society where every successful intervention was liable to be rapidly commodified and brought under control by the system. According to 
them, the irrational and all-encompassing character of the system could only be glimpsed through critical reflection, mediated by difficult art and theory, not opposed or countered directly through political practice.

Gramsci's theory of hegemony is a strategic rethinking of the political with the more orthodox Marxist aim of creating a political revolution out of social praxis. He describes hegemony as a condition in which the development and expansion of one particular group are conceived of, and presented, as being the motor force of a universal expansion, of a development of all the "national" energies' (1982: 182). Under modern conditions political power is secured by the social class that succeeds in working the weave of representations that comprise a national culture so as to create the impression that their interests are those of society as a whole. The autonomy of the political and its distinctive logic are located in the struggle to achieve this. For political representatives of the working class it involves using elements of popular culture to break down the appearance of necessity that attaches to social relations as currently constituted, in order to supplant it with a vibrant sense of the alternative social orderings that are possible.

Writing when Fordist production methods were revolutionising the modern factory, Gramsci already noticed the essential role of new technology in forging the hegemony of the capitalist class. Building on Marx's observation that the power of the workers comes to appear to them as an alien force owned by the bourgeoisie, Gramsci notes that industrial technology reinforces each individual worker's sense of their own contribution as minuscule and unimportant, while their appreciation of the productive capacity of the system is magnified so that it seems overwhelming, like an objective force of nature. ${ }^{4}$ This appearance, he says, is an effect of social power combined with the awesome scale of the new mechanised form of production. In reality, new technology is a historical product and it can be broken down:

For the individual worker, the junction between the requirements of technical development and the interests of the ruling class is 'objective'. But this junction, this unity between technical development and the interests of the ruling class is only a historical phase of industrial development, and must be conceived of as transitory. The nexus can be dissolved; technical requirements can be conceived in concrete terms, not merely separated from the interests of the ruling class, but in relation to the interests of the class which is still subaltern. (Gramsci 1982: 202)

In this way technology was already, in Gramsci's writings, one of the elements in a prevailing hegemony: a weaving together of specific societal interests into a distinctive formation in which one class achieves dominance by seeming to incarnate the objective interests and concerns of the whole. 
The essential dynamic in the theory of political hegemony is the periodic dissolution of seemingly objective and immutable structures through a process of critical action that proceeds in the first instance by unlocking ideas and modes of thought in the political subject. Through revolutionary praxis (that is, action that anticipates or prefigures a superior way of life $)^{5}$ the greater realism and authenticity of that way of living is demonstrated and experienced in practice. Alternative representations of reality then become possible, even necessary, to make sense of this experience, and in Gramsci's theory this is political.

\section{Politicised constructivism: the technical code}

As Feenberg points out (1995), technocracy was the dystopian cultural backdrop that informed the thinking of the previous generation of critical theorists. As the physical incarnation of a pervasive instrumentalism that menaced meaning and threatened to leave society at the mercy of experts whose only concern was efficiency, technology appeared to be beyond reform. In this context, theorists' efforts were largely aimed at defending the possibility of non-technological meaning-making as the true human vocation. ${ }^{6}$ For Feenberg, however, disputes over the meaning of any given technology promise to change the global meaning of technology itself and, ultimately, even hold out the possibility of a change of civilisational model.

In effect Feenberg inverts critical theory's attitude towards technology by identifying it as the locus of political opportunity for radical social and cultural transformation. This move is made possible in large part by his engagement with constructivism, especially the principle that for any problem a technological capability might be used to solve there will invariably be more than one equally feasible design. Social actors select from among the available alternatives, and in this way technology is shaped by, rather than determining of, social relations.

Constructivism places emphasis on how technologies are described by groups of people and on the social processes through which these descriptions become stabilised. Constructivist studies identify the emergence of more than one distinctive vocabulary applied to a technology in its development phase and show how different social groups prefer some descriptions to others because those descriptions tend to produce artefacts that comport with the interest they take in the technology. Once a particular description takes hold, artefacts are reshaped to better suit the interests of the winning group, and in this way their shaping is both symbolic and material. ${ }^{7}$ A new technology is said to be 'stabilised' when one way of describing it becomes dominant, fixing its identity. 
For Feenberg, the importance of constructivism lies in the way that these studies break down the illusion of necessity that inheres in technologies once the shaping process has achieved closure in this way. The authority of technology is undermined by awareness of its contingency on social choices made by human beings, and this is a crucial step in countering its reification - the appearance that technology is something people have to submit to and work with, rather than a thing they might be involved in shaping. The pre-eminence of language in these explanations adds to the feeling of arbitrariness in the events they describe; in effect, social actors might make any kind of sense they like when confronted with a new artefact.

Constructivism has been criticised for detaching its fables of invention and technology development too radically from any wider social picture (Winner 1993). The appeal of constructivist narratives lies at least partly in the way that social groups are manifest in descriptions and appear themselves as social constructs that emerge in the course of engagement with the nascent artefacts. Cycling communities, for example, form around the emergent bicycle rather than as combinations of human individuals already laden with pre-established social histories that affect their attitudes and behaviours. Partly to remedy this, Feenberg folds the basic insights of constructivism into a richer theorisation by replacing the openness of natural language with the Foucauldian notion of discourse and with his own idea of the 'technical code'.

The technical code is centrally concerned with how values get impressed on artefacts at the scene of design and the related question of how technology as a whole comes to be aligned with dominant social groups and to serve their interests. Feenberg agrees with constructivism that technology is shaped by social processes all the way down: there is no, 'inviolate level' (Feenberg 2010: xxiii) of purely technical determination that ensures any one design will be selected from the range of equally effective options. ${ }^{8}$ For Feenberg, constructivism's focus on 'socially relevant groups' abstracts our understanding of social shaping from wider social networks and webs of meaning. Indeed, such is their excessive focus on the sociological minutiae of each case that some constructivist studies even lose sight of anything that connects the disparate instances of technology as technology. ${ }^{9}$

In contrast, Feenberg maintains that the technical code is manifest wherever social interests are at work shaping technology designs. Feenberg describes it as 'the realization of an interest in a technically coherent solution to a general type of problem' (Feenberg 2002: 15). On one side, then, the technical code constitutes some objects as technical, which obliges a certain kind of response from human agents. On the other side, the object's status as technical is conditional on agents responding in this way by incorporating it into their technical practices. 
Resulting designs bear the impress of the technical code and, as a result, they are in alignment with and re-enforce the current social and political hegemony. ${ }^{10}$ As well as informing the actions of proximal social actors, each manifestation of the code 'serves as a paradigm or exemplar for a whole domain of technical activity' (Feenberg 2002: 20).

The 'code' metaphor includes three related sets of ideas. First, as discussed in the previous chapter, it is most essentially the rule under which technical choices are made in view of preserving operational autonomy' (Feenberg 1991: 80). Here the emphasis is on the routinisation of design practice so that choices result in artefacts that support and re-enforce existing power structures. Second, while artefacts are shaped to facilitate the pursuit of certain ends, they must also communicate their function to other social actors and enrol them in relevant activities. ${ }^{11}$ Feenberg writes that 'organisations must encode their technical environment, not merely associating technology with certain signifiers, but installing these signifiers in its very structure' (1991: 81). Finally, the technical code is a discourse in the Foucauldian sense; it is 'a "regime of truth" which brings the construction and interpretation of technical systems into conformity with the requirements of a system of domination' (1991: 79). Here the technical code extends beyond local sites of technology design and is inscribed in norms of perception and practice that pertain to technology but are operative over wide social domains. ${ }^{12}$

Feenberg writes that 'Modern societies ... build long networks through tightly coupling links over huge distances between very different types of thing and people' (2010: 76). The technical code runs through these networks, controlling the description and shaping of new artefacts, where it is a rule of participation: the appearance of technology qua technology, where it is a kind of signification, and extending to the sociocultural horizon, where it places technology in the categorial ordering specific to that society's idea of itself, or its imaginary. At each of these points the technical code is met by countervailing forces that may affect its operation.

For example, a society might become 'more technological', altering the place of technology on its horizon. Feenberg argues that modern societies think of themselves in this way, and that this difference from other cultures (classed as 'traditional') then becomes a matter of identity for people. Similarly, people's expectations and perceptions of what counts as a technology may be altered as a result of ideological or political pressure. Feenberg gives the example of environmentalism, which he says has succeeded in installing the question of sustainability close to the heart of what technology means. Constructivists have shown that disputes arise all the time when new artefacts are in development. Feenberg's theory shows that these conflicts stand in a wider context, and that the technical code invisibly sediment[s] values and interests in rules 
and procedures, designs and artefacts that routinize the pursuit of power and advantage by a dominant hegemony' (1991: 14).

While the outcomes of the contests described by constructivism are not determined, struggles over the meaning of technologies are waged in a distinctive social context. The fact that they are technical in character constrains the choices made by those involved in the design process, ensuring that some values (and corresponding social interests) are more likely to prevail than others. The scene for constructivist struggles has been set, so to speak, by the previous history of such struggles, since these leave a legacy that is both technical and social in character. The technical code, therefore, is always already hegemonic. As Feenberg puts it, 'Since technology is not neutral but fundamentally biased towards a particular hegemony, all action undertaken within its framework tends to reproduce that hegemony' (Feenberg 2002: 63). The prevailing logic of technology design, which he calls hegemonic technological rationality, ensures that the values of managerial control, a narrowly defined idea of efficiency, and a stern absence of other values are pervasive at the scene of design.

However, the fact that a hegemonic order exists and is inherited from the past does not mean that it cannot be challenged. An important point of introducing the code metaphor is precisely this. Using the idea that technology is a constitutive codification of certain objects enables Feenberg to characterise struggles over design as a particular kind of contest with distinctive rules. Regardless of whether social actors realise it or not, in the many small disputes that mark technology design and use, the meaning of technology is at stake and open to change.

\section{Technical democracy}

The idea of the technical code is therefore pivotal for Feenberg's thesis that disagreements over nascent technology design are not mere historical curiosities but, potentially at least, matters of political importance. He develops this insight into a theory of technical politics by drawing on Ernesto Laclau and Chantal Mouffe's development of the idea of hegemony. For them, 'the concept of hegemony supposes a theoretical field dominated by the category of articulation' (Laclau and Mouffe 1985: 93). Their emphasis on articulation grasps the autonomy of political action from infrastructural determinants, while the move to autonomise what might once have been called the ideological 'superstructure' defines their post-Marxism.

Focusing on language as the medium of politics, ${ }^{13}$ Laclau and Mouffe argue that emancipatory struggle has moved from being a matter of rival, class-based articulations of the elements of political discourse, as Laclau 
had suggested in earlier work (1979), to being one in which articulation of difference is the measure of radicalism. According to this theory, the discursive coherence of politics is obtained at the price of fixity, which might be thought of as upholding the law of identity in the field of political and cultural representation. It necessarily entails the withholding of recognition to marginal or misrepresented groups, or to the validity of their claims of unfair treatment. Hegemony is established when antagonism over who and what gets to 'appear' in politics, and get counted as important enough to matter, ${ }^{14}$ is placed out of view by the operation of power. The idea of society as a given, beyond the reach of contingency and articulation, then emerges as a kind of horizon on legitimate political activity.

In this understanding, radical democracy is a permanent political struggle to reopen the question of who and what counts and gets included in politics. Radical democracy succeeds in its struggle against hegemony when 'social logics replace ontological foundations' (Laclau and Mouffe 1985: 183). Prevailing conceptions of what counts as possible or realistic can be changed, and the hold of a narrow, 'common sense' view of society upheld by politics can be loosened by a political practice that deploys strategic re-articulations of the elements of political discourse. When what matters in politics is extended to include new groups and non-traditional concerns, there is a corresponding alteration to the meaning of 'society' and to the kind of limit this represents. The theory of hegemony maintains the neutrality of the elements of political discourse until they are combined in determinate articulations, which can reflect either this focus on difference or the attempt to close it down and affirm established identities.

This conception of politics as an agonistic, discursive practice shaped by articulation mirrors Feenberg's notion of formal bias in technology design. As seen in the last chapter, he emphasises that the technical code works through concatenations of neutral technical components, which produce designs that are only biased in context. Interestingly, however, Laclau and Mouffe exclude technology from the field of contingency and articulation. The struggle for hegemony is waged in terms of control over syntactical elements of political discourse, and while the areas of life that are open to articulation in that way expands in the capitalist era, ${ }^{15}$ it does not extend to those dimensions of the social formation that are paradigmatic, or systematised. For this reason, they exclude things like the 'reorganization of an ensemble of bureaucratic administrative functions according to criteria of efficiency or rationality' (1985: 136) from the politics of hegemony because such practices are not located in contingency. ${ }^{16}$

Undeterred, Feenberg presents the struggle over the meaning of technology as an instance of hegemony and radical democratic counterarticulation. Hegemony is a form of power that operates through media 
(popular culture, political 'news' media or indeed technology) in which opposed parties find themselves operating. The idea of hegemony enables a rethinking of power in terms of strategic dynamics rather than as a matter of static, structural confrontations of parties with clear and opposed interests deriving from an exploitative economic base. It rests on a conception of politics as autonomous from economic and social correlates, and as a domain that involves participants making plays for a kind of positive association, or equivalence, with key elements of the surrounding culture. By appearing to be more in tune with the concerns of the people as a whole, a party or group can shift the ground of debate and ultimately win control of the state. In this way, political parties present themselves as sharing meanings with the populace. For radical democrats, winning hegemony involves such a play of ideas to win recognition for groups that have been excluded from political representation. Success in this will change the meaning of 'society' and at the same time shift the prevailing idea of what is possible. Laclau and Mouffe argue that this strategic conception of politics is superior to a more Marxist approach that makes direct, reductive appeal to class or other interests.

Just as with the terms of political discourse, hegemony in technology design works through the imposition of a determinate articulation of elements that reflect the interests of one group, while excluding those who do not count.

The technical code defines the meaning of technology and sets limits on what it can be expected to do, in the same way that political hegemony encourages a restricted idea of what society can be. As Gramsci already understood, the illusion that technology is an independent power over which people can exercise no control plays a key role in both these scenarios. The phases of a standard constructivist account of technology development can be recast in light of Laclau and Mouffe's ontology of lack, disclosing their fuller, theoretical significance.

For them, political struggle emanates from a primal antagonism that is held out of view by politics. This antagonism is, in their terms, displaced by political agonistics. ${ }^{17}$ The goal of radical democracy is to change the terms of this displacement, so that those who have traditionally only been subject to domination by hegemonic power can instead play an active role in shaping society. The notion of a realm of antagonism that is located outside the field of representation but which nonetheless shapes it applies equally well to technology. Faced with absence, or a generalised incapacity in the face of nature, there is perhaps an omnipresent struggle to create, to make something out of nothing, which is primal to the human condition yet poorly understood.

Enigmatic and in some ways unrepresentable, invention gives rise to new technological elements which form the basis of the competitive dispute between 'relevant social actors' described by constructivism. In 
the early stages of a technology, often the focus of constructivist studies, design appears to be an open field associated with free creativity and play unencumbered by substantive or historical determinants. This is covered over when the process becomes agonistic, or in constructivist terms when the meaning of an invention is questioned and disputes arise, perhaps fuelled by a justified sense that different, equally practicable designs working with the same capabilities serve opposed social interests.

Establishing the dominant, hegemonic image of technology as a whole (in modern societies as the authoritative and exclusive domain of expertise) is both a condition of victory in this struggle and one of its outcomes. When technology has been subject to hegemonic codification this is because creativity and experimentation have given way to conflict over meaning and representation, culminating in the decisive impress of hegemony. This is understood by constructivism as 'stabilisation'. At this point, the technical code confers a seemingly fixed, ontologically certain identity on the resulting technology, making it appear as part of the technological given and, as such, immutable and beyond question.

Feenberg envisages progressive technical politics as attracting 'a democratically constituted alliance of actors, embracing all those affected' (2010: 80) by specific technologies. Technical politics is a matter of introducing different social logics into the operation of the technical code and, in this way, changing what counts as legitimate technical practice. He gives a number of examples of this, such as his account of Minitel users who transformed an early French computer network from an electronic phone book into a dating agency (Feenberg 1995, chapter 6). In so doing, he argues, they shook the equipment free from its symbolic association with the state, organisation and efficient communication and broadened its range of uses. He also discusses the example of HIV and AIDS patients (1995: chapter 5) who, faced with the prospect of having to wait for new drugs to pass through extensive trials, campaigned to change the rules on drug testing so that they could participate and, in so doing, gain earlier access to life-saving medicines.

In both these cases technical practices were opened up and modified by groups who had previously been thought of merely as recipients of technologies. Their activities were aimed at securing a more active role in which they gained representation as agents who could 'speak' for themselves, and as a result they reconfigured the operation of the technical code. The first changed the image of the computer network, overwriting predefined functions and forcing it to accommodate communicative cultural uses. The second asserted an active role for patients in choosing what level of risk they were prepared to take in their search for a cure. In both cases this re-articulation of the code creates equivalences (networks $=$ communication $=$ culture , experiment $=$ risk $=$ choice $)$ that were not salient in the previous order of things. It is by no means 
implausible, if a little bit speculative, to suggest that these local changes were associated with wider changes to the meaning of technology, reflected in the place people subsequently assigned to it in their mental image of society.

Feenberg suggests that examples like this illustrate the possibility of a democratic challenge to the operation of the technical code. He gives several reasons for construing matters in these terms. First, the presence of more people in the design process will in itself have consequences for the technical code because larger groups will be more sensitive to risks presented by new technologies. More vulnerable members of society are often disproportionately affected by such hazards, so their inclusion in the design process will mitigate this. In this way, wider public involvement will necessarily create resistance internal to the design process. The overall goal of radical democratic technical politics is to safeguard the scene of design so that it is free from influence by powerful social groups. Success in this should be seen as creating a 'protective umbrella under which social creativity can operate at the micro-level of particular institutions and workplaces' (Feenberg 1991: 61).

Potential is protected beneath the umbrella and glimpsed in different articulations of the technical code. Resistance to dangerous or hazardous innovations, for example, might tip over into different articulations, as when workers succeed in imposing safety standards on the design of boilers. New potentials that would be overlooked by the existing hegemony become available in the course of the design process and might, in principle, be developed at any time. Feenberg is cautious on this point, however, because the aggregate effect of multiple new articulations expressing counter-hegemonic social logics that will 'guide the design of future technology' (1991: 125) would be a new technical code, producing different rules for the selection and concatenation of technical elements. It is more important to retain the idea of potential as something that haunts the current hegemony than to linger too long on the question of its possible future as a new, utopian technology - a point I return to in Chapter 5.

The question of potentiality is closely related to the theme of agency at the scene of design. Designs shaped by the hegemonic articulation of the technical code will tend to re-enforce the impression that technology is beyond people's control, discouraging non-credentialised people from participation. Feenberg expresses optimism about deepening and extending agency - it is the motor principle of his technical politics. But of particular importance here is the extent to which human individuals now have agency within the technical sphere, and the contrast between this and the situation in other areas of culture. As Feenberg notes, 'despite discouraging developments in other domains, agency in the technical 
sphere is on the rise' (2010: 55). He associates this with changes to the technical infrastructure itself, writing that in digital culture,

We are witnessing the end of dystopia as the defining technology of our time shifts from great centralized systems such as electric power and broadcasting to the more loosely structured world of the computer. (Feenberg 2010: 57)

Far from being put off by Laclau and Mouffe's exclusion of systemic properties from the sphere of radical contingency, Feenberg's use of radical democratic theory is to some extent a colonisation of it as well, such is his sense of the importance of technology to contemporary social and political dynamics. He writes, for instance that, 'the social imperatives of capitalism are experienced as technical constraints rather than as political coercion' (2002: 69). This suggests that struggles over the articulation of the technical code are not running in tandem with contests for control of political discourse but actually supplant the significance of the latter. Feenberg is not only saying that he has identified in technology a chink in the armour of the hegemonic system but is also making the stronger claim that it is the only opening available. Traditional politics and even other areas of culture are less important in the dual sense that they do not play the leading role in administering contemporary society and, in contrast to technology, they present no realistic possibilities for active resistance. ${ }^{18}$

\section{Moving the boundary of technique}

The technical code reifies objects that had previously been open to further determinations and social disputes over their meaning and ultimate form.

This brings them into a chain of equivalences with other technical objects, which ensures they all appear to be technology, with the authoritative presence entailed by that in modern societies. ${ }^{19}$ For this to occur under current, capitalist conditions means that any technical object thus constituted contributes to the centralisation of power in a hierarchical social system and enhances the operational autonomy of managers within the production process.

Feenberg emphasises that technology is a dependent social variable, something that is shaped by social activity all the way down: indeed, it is a 'social battlefield' (2002: 15). This activity is always ongoing and dynamic; technological reality is in a permanent condition of flux. As we have seen, for Latour and others, the idea of technology is a contingent product of multiple social situations and nothing more. In other words, it is an idea that may in fact be redundant if the diversity of these situations is such 
that it pulls it apart, so to speak. In that circumstance, the idea of technology would simply lose its practical salience and cease to function as what Latour calls a 'collector' (2013b).

This description of the reality of technology as a process that might cease to coagulate in a singular social entity comports with Feenberg's suggestion that technology's essence is thoroughly historical. However, for critical theory the imposition of discursive identity cannot be abstracted from questions of social power. The dominant representation of technology is something more than a mere idea, and loosening its hold is not the straightforward matter that Latour seems to think but involves social conflicts and political struggle. Technology is a mode of appearance of objects that has real social consequences, including those that were the focus of the last chapter. The solidification of technology into the 'material framework of modernity' (Feenberg 2002: 19) is wrought through social processes, but these are not only linguistic choices - they reflect the balance of power in society. Reification brings the contested aspects of any given technology development to an end and imposes stasis. This fixes its identity and pins it down in relation to the prevailing idea of technology as such, which includes a prescriptive sense of what it is for, who may use it, and under what circumstances.

What Feenberg calls 'the boundary of technique' is the inscription of necessity in technologies: the sense that they must be accepted and complied with because they embody the 'correct' technical solution. Whereas in technocracy this boundary was set by large corporations and few would ever have thought to question a machine beyond learning how to operate its front end, in recent decades the increased willingness of diverse social agents to challenge technical designs and subvert authorised patterns of use has created more instability. ${ }^{20}$ This change discloses that 'the boundary of technique is never clear. In fact, identifying that boundary is one of the most important stakes in the struggle for and against alienated power' (Feenberg 1991: 58-59).

Democratic technical politics aims at shifting the boundary of technique by making more technical practices open to exploration and experimentation by wider segments of the population. This process, which Feenberg calls democratic (2002: 92; 2003), subversive (1992) or sometimes progressive (2017: 220-222) rationalisation, will bring the operation of established technology more into line with society's needs and interests. To achieve this, democratic agency has to temporarily dereify technology, which must involve 'coding' it in a way that is heterogeneous to the technical code as currently constituted.

As seen above, Feenberg gives examples of popular interventions in the field of technology design that succeed in altering technical practices and perhaps in displacing the overall meaning of technology. His suggestion is that activities like this alter the dominant conception of 
what technology is, sometimes by restoring a sense of its true purposes. In the example of the patient-activists, the established image of medical experts and scientists in lab coats working in accordance with abstract protocols that laypeople had to respect without really understanding gives way to a more straightforward representation of scientific and technical practices as involving real people making decisions that are consequential for other human beings. In this way, technical-political action breaks down the illusion of technique and replaces it with something more sociologically messy, but also more realistic.

The extent to which agency is now present in the technical sphere means that, for Feenberg, the age of technocracy has passed and it is meaningful to think of 'technical politics'. The process of reification that created technology as a fixed institution is now prone to challenge in the sense that people can discern their own role in producing what counts as technology, and this means that they can make choices that change the technical code, with potentially far-reaching implications for what technology is and what it might become. This is a political radicalisation of the constructivist thesis that different social groups may challenge technology design and that these contests 'shape' the resulting artefacts. It adds to that argument the observation that when they are successful, democratic interventions in technology design can change the meaning of technology by moving the boundary of technique.

As seen in the previous section, according to radical democratic theory, power differentials are the consequence of an ontological contradiction concerning the necessary yet impossible character of society. A social imaginary must be achieved, and yet the social idea can never be finished, completed and stabilised as self-identical. Since it is both utterly necessary for everyone to know that there is a society and objectively quite impossible for them to achieve this, there is an endless struggle to establish institutions, patterns and stability that can retain the confidence of the majority of social subjects. In a sense, they are all compensating for the fundamental lack identified above. This struggle defines the political, and the fact that different groups seek to make theirs the dominant representation makes it agonistic. Feenberg's technical politics, indeed Feenberg's entire dialectic, rests on construing technology, and especially the politics of technology design, on this model.

The point of radical democratic technical politics is to widen the scope for technical interventions by individuals and groups whose current relation to technology is the subordinate one of the worker-user. For them, technology is encountered as something overbearing and authoritative and this is associated, by the hegemonic articulation of the technical code, with its effectiveness. Behind the reified appearance, though, there is real antagonism which technical politics brings into view. Interventions like hacking a communications system, modifying a drug testing regime or 
demanding better safety standards on industrial machinery break down the illusion of technology as objectively necessary and create new spaces for agency and resistance. In this way they restore a sense of the technical as a locus of antagonism. Once the use and design of technology has been problematised and brought into the realm of meaningful choice for nonexpert groups, then the question of social power looms large.

Laclau and Mouffe's theorisation of the political invokes a particular relationship of politics to ontology, which in some ways is highly felicitous for Feenberg's project. Just as constructivism rests its struggles over meaning on the assumption of underdetermination, so technical politics is underscored by the indeterminacy of technical elements, whose concatenation in different designs produces social conflict and competition. Feenberg's contention is that technical politics is an agonistic struggle involving diverse technology users on one side and dominant social interests, especially managers, on the other. The struggle waged by these actors is primarily a struggle over the kind of technology society gets, and is conducted at the scene of design or use, but because technical politics involves breaking down the illusion of technique its ramifications add up to establish the possibility of what Feenberg envisages as a more democratic technology. This would involve moving the boundary of technique to a position consistent with socialist transition.

Progress in technical politics, then, disabuses us of what Feenberg calls the 'technical illusion' Technology is widely perceived as liberating because it appears to free people in various ways from tricky worldentanglements. While acknowledging the efficacy of technology - it really does solve problems, enable societies to do things differently, achieve more with less effort, etc. - Feenberg emphasises that there is also an illusory element to this. By opening up technical practices to a wider range of social logics, democratic technical politics is a struggle over the dominant representation of technology.

It is clear from this that Feenberg's ontology is not at all the same as the essentialist one of some substantivist philosophers. Technology is whatever it appears to be in any given social formation, but this appearance, Feenberg argues, has a distinctive, albeit illusory, solidity and permanence that qualifies it as 'technology'. As technical infrastructure, technology seems to perdure, to be something more or less immutable, yet at the same time it is a human product susceptible to redesign and even obsolescence and replacement. The illusion of technology's solidity is an instance of reification, in which a human product comes to appear as something alien, powerful and beyond human control. This way of thinking about what technology really is - as contingency that manifests as a certain kind of permanence, somewhere between illusion and reality - comports well with Laclau and Mouffe's negative social ontology. 
Technical politics, then, has two layers or aspects, one concerning the war of position over current technical designs, the other more forwardfacing and concerned with the place and character of technology in an alternate civilisation. The first lies within the field of articulation as just described, and involves opening up the technical code to diverse social logics that may subvert the hegemonic ordering. The second layer draws on the negative ontological conception of technology with its source in antagonism to identify neglected potential as the basis of a future with a different technical reality. As we will see in the next chapter, this second layer of technology transformation involves an infusion of meaning and value into technical practices.

For Feenberg, the second layer is essential to critique because it is the realisation of human potential for a more meaningful world-relation that connects up the multiple real-world instances of technical politics, from computer hacking to patient activism. These activities are unified through the idea of released potential. Once technology has been opened up to democratic participation, critique faces the question of what it is in any given articulation or 'sort' that connects it to others, and permits the theorist to align them as manifestations of a single counter-hegemonic strategy. The ontological layer of technical politics is Feenberg's framework for answering these questions.

The essence of Feenberg's proposal is that there is a kind of unifying thread that connects such instances of unexpected popular intervention in the previously circumscribed domain of the technical. Ultimately, he believes that interventions like this have the political potential to facilitate the kind of transformation of technology that will add up to wholesale civilisational change. Pursuant to this, he suggests that the meaning of technology has already changed as modern societies have left the 'dystopian' constellation that preoccupied his critical theory forebears. This coincides with digitisation, ${ }^{21}$ and the primary result is that the social logics that might articulate the technical code have become more diverse and in consequence its entanglements with other dimensions of social power more complex. The fault-lines, therefore, where contests over technology design and use occur and shape the meaning of technology have also moved. Feenberg acknowledges this, but his model for technical politics remains premised on a confrontation between technological hegemony on one side and potential-releasing, democratic participation on the other.

Feenberg's emphasis on hegemonic technological rationality leads him to posit radical democracy as the privileged counter-value through which space might be created for rival social logics to articulate the technical code. This accommodates a widening of the range of values that might apply to technology design, which makes feasible the kind of civilisational transformation he envisages. However, the new constellation, in which 
more people are actively shaping technology and technical objects are themselves more active in diverse, unpredictable ways, is different, but it may not take us any closer to machines whose design contributes to a more humanised world.

As we saw in the last chapter Feenberg insists that democratic rationalisation cannot proceed in an instrumental fashion and, equally, that it cannot be a (utopian) matter of wishing nicer machines into existence. Technology holds a distinct structural position in society and has internal protocols that must be respected in any account of the reform process. This means that while design is an important opening for political practice, it must be embedded in an account of wider transformation. While constructivism enables Feenberg to open up the scene of design, so as to think the possibility of people making demands and shaping technologies in a politically motivated direction, he is also wary of the charge of utopianism. ${ }^{22}$

\section{Ambiguities of rapid politicisation}

Feenberg's idea of the technical code represents a significant advance over earlier versions of constructivism. Without this idea, constructivism cannot account for the persistence of the distinction between technical and non-technical objects, still less explicate what that distinction connotes in contemporary culture. Through it, Feenberg also succeeds in giving renewed political impetus to critical theory, bringing its sense of contradiction and antagonism to the study of a growing arena of political struggle.

The idea of technical politics is, then, a major enhancement to constructivism, giving it a political relevance it otherwise lacks. Feenberg's concept restores the critical tension between technological reality, which is messy and disparate, and the salient conception of technology as something authoritative and final. Where hackers, game modders, social media users, etc. run up against corporate platforms and state controls on internet and technology use, he has identified a burgeoning area of contemporary experience in which critical theory might both gain some traction politically and facilitate a fuller understanding of the meaning of these conflicts.

Using the constructivist insight that technology is socially malleable and susceptible to reform by the power of redescription, Feenberg suggests that it is now the principal medium of political struggle, displacing other forms of public discourse and contested institutions. His examples demonstrate that small-scale technical interventions can have extensive consequences, up to and including effects on the very meaning of technology as a whole - its place and significance in society and 
culture. In this way, Feenberg redirects critical theory's traditional suspicion of expert discourses into a political opposition of the perspective of ordinary 'users', who for him represent democracy, to those whose technical credentials are a condensation of knowledge (of how things work) and power (over those who only use the things).

Feenberg's work is therefore optimistic about the prospects for democratic reform in the sense that he finds progressive significance in much of what is currently going on and interprets the vibrancy of contemporary techno-culture as confirming his thesis of an emergent technical democracy. There are reasons to be doubtful about this, however. Feenberg's favoured theory of radical democracy might be considered to promote a positive outlook, with lots of activities available to be easily cast as manifestations of democratic resistance because they represent non-compliance with the hegemonic articulation of the technical code. However, if an agonistic model of activity is presupposed, then this may dispose the analyst to find resistance everywhere, especially if the technical has itself been construed as co-terminous with the political.

Earlier versions of critical theory understood the problem of technology in terms of experts using the authority of technology to dictate terms to technology users and, ultimately, imposing an unquestioning compliance on the rest of society. Technical politics is Feenberg's way of thinking through openings that have ruptured this scenario, and democracy is an important value in that process. However, with the change of cultural horizon involved in breaking with dystopia, technology has already shed its association with the unquestionable authority of experts, or even with narrow efficiency as a goal. The diffusion of digital technologies has encouraged the development of diverse cultures of experimentation, dabbling, reconfiguring, sabotage and so on. To the extent that the Internet, for instance, is a place where everyone periodically plays with technology, and mobile phones have become toys that people trust and incorporate into every aspect of their lives, what Feenberg calls the technical illusion has already evaporated.

Much of this activity would have been unthinkable just a few decades ago, and this must be at least partly attributed to the fact that technology now exists in networks that extend into places not primarily associated with work and control. These networks produce and are produced by articulations of the technical code that are embedded in cultural values like play and learning, rather than control or efficiency. Technology is as likely to be held equivalent to things that can be trusted, that are lifeenhancing, individual, even eccentric, as it is to be associated with corporate power or government control.

This is not to say that the technical code has lost its connection with social domination. On the contrary, the entwinement of technology's network with those of social power seems to be as profound and pervasive in 
its consequences as ever. Under this changed cultural horizon, however, the technical code is no longer subject to one or two kinds of articulation. Feenberg himself makes this point when he writes that 'technical rationality consists of various loosely related dimensions with different social implications' (1991: 178), but he does not draw the necessary conclusion for technical politics from this observation. If diverse rationalities are present in technology, then the competing values at stake are also already multiple rather than binary.

The usefulness of the technical code idea is compromised by Feenberg's imposition of a binary political battle concept onto it. His conception of technical politics as an agonistic struggle between democracy and hegemonic technological rationality effaces sociological and political details that are, in consequence, left out of account in the theory of technical politics. As we have seen in this chapter, Feenberg's claim that technology is the principal or even the only vehicle of hegemonic power in contemporary society even threatens the wider theory of radical democracy with absorption into technical politics. His assertion that the technical code is the vehicle of contemporary hegemony may be a feature of theories, like Laclau and Mouffe's version of radical democracy, that rest on negative ontological foundations. A fundamental antagonism defines the field and gives it its agonistic structure, but it also seems to entail that other fields cannot also be fundamental.

Lois McNay has argued that this kind of overreach is a pervasive feature of theories she characterises as pre-emptively motivated to present aspects of social reality as political. In her critique of Mouffe's work in particular, McNay argues that the logic of social being exceeds the explanatory force of the one-dimensional antagonistic logic of signification' (2014: 8). In other words, those processes that stand beyond the reach of political discourse are not merely amorphous, or the locus of an unrepresentable antagonism, but reflect the presence of important dimensions of social reality studied by other disciplines. She points out that social processes, including those involving symbolic violence, recede in radical democratic theory to become an undifferentiated 'blob', obscured by the overbearing, fascinating logic of the political.

In this respect technical politics mirrors radical democracy's 'linguistic universalism' (McNay 2014: 18), assuming that everyone is involved with technology in much the same way that Laclau and Mouffe assume everyone would have the capacity to participate in political speech, were it not for the way that politics is currently structured. The under-representation of social groups (women, some ethnic groups, people with some disabilities) in technical professions is a long-standing concern of sociologists of technology (Wacjman 2004). Technical politics neglects to include any space for the multiple social causes of their marginality. Instead their exclusion is viewed solely as one of the negative 
consequences of hegemonic technological rationality, perpetrated by formal bias in technology design. This fails to address the exclusion of groups of people who never encounter a codified technical object, some of whom decide at an early age that technology is 'not for them', perhaps as a result of internalising a sense of inferiority to experts and knowledgeable men. Sociological processes that limit and inhibit women's interest in technology, for example, are not themselves reducible to the codification of technology as male - it is one factor among many, and it needs to be understood through a wider, sociological lens. The danger here may be that in rushing to conceive technology as politics, critical theory fails to challenge the fine-grained, social processes through which privileged forms of access and technical control are reproduced, or to accommodate any account of the social processes through which those who are excluded from a role in technology might thematise their exclusion, gain recognition for it and turn it into a political issue.

If Feenberg's use of radical democratic theory effaces sociological questions around human agency, it also obscures the active, substantive role of specific technologies, which also tend to be viewed in binary terms either as threats, because they instantiate the hegemonic technological rationality, or as signs of an as yet quite abstract potentiality. Feenberg's thought remains conservative in this sense. While it might be expected that democratic challenges to capitalist hegemony would create openings for new ideas and designs that embody different values, his discussion of the latter never strays beyond recurrent reference to the notion of a currently neglected potentiality. The social (ontological) reality of technology, he argues, is matched by an idea of latent human or social potential. He writes that 'it is important to retain a strong notion of potentiality with which to challenge existing designs' (2002: 33), but this allusion to potential is as far as the theory goes in projecting an alternative version of the technical code.

The question of potential brings us to a further problem with the theory as currently formulated, which is that the benefits of democratisation are nearly always presented as essentially negative, or defensive. As we saw in the last chapter, Feenberg opposes conservative strategies aimed at containment of technology from positions in culture outside technology (for example, restrictions on embryo research), yet he is equally clear that the primary beneficial consequence of democratisation will consist in checking certain kinds of technology design from within. This might seem to betray an ongoing concern with technology as a threat, reflecting Feenberg's belief that current technology is a reified version, shaped by capitalist interests. Defining technology as a social process, he envisages democracy as a restraining force within technology design, holding negative developments back, rather than an externally imposed cultural constraint. However, while inhibiting hegemonic distortions from within in 
this way is, perhaps, a necessary first step, it is not clear that installing cultural constraints as internal to the design process is a sufficient condition for further progressive change.

If Feenberg is evasive on the nature of this positive potential, he exaggerates the extent to which the multiple interventions that constitute democratic rationalisation really are internally connected as manifestations of progress, with the overarching implications for the system that he ascribes to them. It is not clear that subversions of established uses of technology are always steps towards democracy, even when they improve the lives of specific groups of individuals. Patient activism has shortened the time spent testing new drugs and saved lives, but it is questionable whether it amounts to, or even contributes to, progress in any wider sense. A popular challenge to expertise cannot be considered a step in a progressive direction merely because it questions technical authority, illustrated by the fact that Europe and North America are currently in the midst of a measles epidemic, perhaps partly caused by popular scepticism about vaccinations.

Similarly, computer hackers have shifted the boundary of technique in the sense that they have promoted the idea of the computer network as something non-expert people may use as a medium of selfexpression, but the sociology of this does not involve enhancements to democracy. Instead, the diffusion of accessible networked computing has been associated with the emergence of cultures (such as those associated with hacking and gaming) in which informal hierarchies of expertise and patterns of social exclusion are rigidly and often aggressively enforced. These developments have been associated with criminal organisations' use of networks and, partly in consequence, with repressive legislation that criminalises certain forms of computer use (Chandler 1996) and constructs a new, normativised conception of the 'user'. It is true that in the digital era, customising technology and shaping it to one's own requirements has become a normal part of life for perhaps the majority of people. However, inequalities persist and proliferate within this culture of diffuse technical know-how, and there has been no corresponding progressive change that might merit description as 'democratisation'.

Democracy, it seems, does not play the transformative role in technical politics that Feenberg assigns to it, even if popular interventions of the kind he identifies do create space for alternative values which might shape the technical code of the future. Moreover, when it has been applied to technical systems democracy has not always led to their ethical improvement when viewed in historical perspective. There is no easy association of democratisation with the ethics (or aesthetics) of a superior civilisational model. Feenberg envisages 'mutually supporting transformations' (2002: 27) as if they were a natural consequence of 
loosening the grip of the technical code. But numerous examples, such as the practice of eugenics in Sweden in the 1970s, suggest that the finest democracy can go together with abusive medical (and other) technologies. Perhaps the underlying problem here is that the very conditions that make democratising technology design thinkable also vitiate any notion of progress: in pure democracy the future has no direction aside from the one people choose to give it.

It is perhaps for this reason that Feenberg approaches the notion of a future technical code with a degree of caution. There is inconsistency between the idea of technical politics as an open-ended play of articulations, widening the circle of included participants while always struggling against hegemony (against a background of antagonism), and Feenberg's Marcusean orientation towards reconciliation and harmony (with something like Marx's 'end of history' providing a sense of direction). Perhaps the multiple struggles over technologies and the changes they bring about do not add up to anything like progress in the Marcusean sense. This probably depends on the kinds of values that get imposed on technology and the extent to which they finesse Feenberg's notion of potential. The next two chapters address this.

\section{Notes}

1 'Manual' here is a placeholder for the authority that guides users in their initial engagements with machines and other artefacts. It includes instructions from the boss at work, conventions and patterns of use sedimented in the bodies of workers as habits, and even visual metaphors in a graphical user interface.

2 The idea of hegemony antedates Gramsci's intervention, though the latter has become the definitive point of reference. Perry Anderson traces the origins of the modern concept to nineteenth-century debates over nationalism and the state, where it signifies the role of a unifying power, and notes that with Gramsci's intervention, 'hegemony ... acquired two enlargements of meaning in tension with each other. It now included both the extraction by rulers of consent from the ruled, and the deployment of coercion to enforce their rule' (Anderson 2017: 21).

3 This does not mean he was any less perceptive a critic of the negative effects of reification on psychological and cultural life. As Boggs puts it, 'Gramsci pointed to Taylorism in the US and the fascist corporate state in Italy as harbingers of the most sophisticated mode of capitalist domination, in which workers would be totally subordinated to machine specialization and the cult of efficiency. The diffusion of bureaucratic-technological norms would mean the destruction of all intellectual, artistic, and even human content to production and, in the end the grinding down of the workers' life to virtual nothingness' (1976: 47). Gramsci refers to the spread of psychoanalysis as a symptom of 'the increased moral coercion exercised by the apparatus of State and society on single individuals, and of the pathological crisis determined by this coercion' (1982: 280). 
4. The affinity with reification is clear when Gramsci writes that 'One of the commonest totems is the belief about everything that exists, that it is "natural" that it should exist ... and that however badly one's attempts to reform may go they will not stop life going on, since the traditional forces will continue to operate and precisely will keep life going on ... One may say that no real movement becomes aware of its global character all at once, but only gradually through experience - in other words when it learns from the facts that nothing which exists is natural ... but rather exists because of certain conditions' (cited in Boggs 1976: 110).

5 In his Prison Notebooks, which were scrutinised by a fascist censor, Gramsci's phrase for Marxism was 'the philosophy of praxis' (Gramsci 1982). A similar emphasis on praxis is found in other Hegel-inspired Marxist scholarship, such as the work of Karl Korsch (1970) and, of course, Georg Lukàcs (1981). Steven Vogel (in Arnold and Michel 2017) provides an interesting discussion of the epistemic function of praxis in Feenberg's thought.

6 Even Marcuse's notion of a new technics as the exit point from onedimensional society is suggestive of a social imaginary in which technology and technologists play a controlling role.

7 This point is emphasised in some constructivist studies. For example, Bowker and Starr suggest that 'classifications and standards are material as well as symbolic' (1999: 39). It tends to be assumed that the two aspects are inseparable: motivated relabelling drives physical amendment and substantive alteration is reflected in changes of terminology.

8 'Technology must really work. But it is not merely because a device works that it is chosen for development over many other equally coherent configurations of technical elements' (Feenberg 2002: 79).

9 'The more one studies technological arrangements, the more one considers their ins and outs, the less chance one has of unifying them in a coherent whole' (Latour 2013b: 213).

10 Wiebe Bijker acknowledges that in most constructivist scholarship there is a 'missing link' between these details and the question of power (1997: 261). It is this link that Feenberg's idea of a technical code tries to provide.

11 Feenberg refers to a scale of meaningfulness for technological artefacts, ranging from 'semantic impoverishment' to 'richest object relations' (2010: 175).

12 In this it corresponds to what Bowker and Star describe as a classification system, forming 'a juncture of social organization, moral order, and layers of technical integration' (Bowker and Star 1999: 33).

13 And all other practices: their theory has been accused of 'absolutising' language (Geras 1987), in common with its post-structuralist sources.

14 'To enumerate is never an innocent operation; it involves major displacements of meaning' (Laclau and Mouffe 1985: 62-63).

15 'The hegemonic form of politics only becomes dominant at the beginning of modern times, when the reproduction of the different social areas takes place by permanently changing conditions which constantly require the constitution of new systems of differences' (Laclau and Mouffe 1985: 138).

16 Laclau and Mouffe write that in 'industrial society there is a growing unification of the social terrain around the image of the mechanism' (1985: 36), which perhaps reflects the hold of a particular hegemonic conception of technology 
on their thought and surely represents a regression behind Gramsci's insights, cited above.

17 Allan Dreyer Hansen usefully describes Laclau and Mouffe's theory in the following terms: 'Discourse theory's ontology consists in a set of limits and impossibilities, and its theorizing is based on these. It starts from the basic claim of the "impossibility of society" and the essential unfixity of all possible social objects. Society is impossible because it is "haunted" by an unsurmountable negativity ... which cannot be sublated in any dialectical movement ... Radical negativity means that it cannot be positivised by a deeper objectivity (e.g. the cunning of reason, society's movement of stages towards communism, etc.)' (2014: 286).

18 Feenberg writes that 'natural science and technology define the framework of capitalist civilization after World War II' (2002: 167), and that nothing less than 'the meaning of modernity is at stake' in technical politics (2002: 114). He also emphasises that human beings are now in technology - that is, immersed in a technological environment and shaped by it to a new, unprecedented extent.

19 It should be noted that the integration of new technologies into this system of representation is not often seamless. New technologies tend to destabilise what technology means, with implications for associated power structures. Feenberg writes that 'new technology can threaten the hegemony of the ruling groups until it has been strategically encoded' (2002: 79). After that, however, once it has received the technical code, 'everywhere technology goes, centralized, hierarchical social structures follow' (2002: 24).

20 Latour is the ideologist of this tendency: he abstracts it from questions of social power and presents the dissolution of technological hegemony as if it has already happened.

21 Relatively early in the digital transition, Feenberg observed that it matters what we do about technology because, perhaps for the first time in history, public involvement is beginning to have significant impact on the shape of technological change' (1995: 2).

22 Marcuse was famously accused by Habermas (1989) of naively recommending a dialogue with nature because he moved too quickly in developing his vision/ fantasy of a radically different technology. 